\title{
Inhibition of ear-emergence time and sensitivity to day-length determined by the group 6 chromosomes of wheat
}

\author{
M. N. ISLAM-FARIDI†, A. J. WORLAND \& C. N. LAW* \\ Cereals Research Department, John Innes Centre, Norwich, NR4 7UH, U.K.
}

\begin{abstract}
Increased dosage of the group 6 chromosomes of Chinese Spring wheat delays ear-emergence. Reduced dosage of the same chromosomes has the converse effect and accelerates emergence. Both effects are removed by vernalization. It is proposed that genes on these chromosomes produce a flowering inhibitor, sensitive to vernalization. It is suggested that this inhibitor may be affected by the major $V r n$ genes for vernalization requirement on the group 5 chromosomes through their production of a flowering promoter which either suppresses the group 6 genes or complexes with the inhibitor, thereby accelerating ear-emergence. A gene (or genes) for sensitivity to day-length was detected on the long-arm of chromosome $6 \mathrm{~B}$ which, in its absence, delayed ear-emergence under short days. The genes for inhibition of emergence were also probably located on the long-arms of the group 6 chromosomes, but were separate from the gene(s) for day-length sensitivity.
\end{abstract}

Keywords: day-length, ear-emergence time, flowering inhibition, group 6 chromosomes, wheat, vernalization.

\section{Introduction}

The major genes controlling variation in the earemergence time of bread wheat, Triticum aestivum $(2 n=6 x=42)$, are now becoming well characterized. Homoeoallelic genes for vernalization requirement, Vrn1, Vrn4 and Vrn3 (Law et al., 1976; Maystrenko, 1980; Stelmakh, 1993) are located on the long-arms of chromosomes 5A, 5B and 5D, respectively. Similar homoeoallelic genes, $\operatorname{Ppd} 1$ and $P p d 2$, affecting the response to day-length have been found on chromosomes 2D and 2B (Klaimi \& Qualset, 1973; Welsh et al, 1973; Scarth \& Law, 1983; Worland \& Law, 1986). An effect of chromosome $2 \mathrm{~A}$ on the response to day-length has also been observed (Law et al, 1978; Islam-Faridi, 1988), so that it is likely that a further homoeolocus, $P p d 3$, will be located in the near future. These two sets of genes appear to be the predominant genes influencing the global adaptation of wheat. The $V r n$ genes determine the division of wheat into spring and

$\uparrow$ Present Address: Department of Soil \& Crop Science, Texas A \& M University, College Station, Texas 77843-2474, U.S.A.

*Correspondence. C. N. Law, 41 Thornton Close, Cambridge CB3 ONF, U.K. winter forms, and the $P p d$ genes the ability of wheat to grow and flower under short day-lengths. This is an essential requirement in India and Pakistan, Australia, Mediterranean countries and many other areas of the globe where, because of high summer temperatures, wheat growing is restricted to the cooler but shorter day-lengths of winter.

Other genes affecting the progression to flowering have been reported. A gene sensitive to vernalization, $V r n 5$, has been located on the short-arm of chromosome $7 \mathrm{~B}$ of the substitution line Chinese Spring (Hope 7B) (Law, 1966). Chromosomes from most of the homoeologous groups have been cited as influencing ear-emergence times (Morrison, 1960; Halloran \& Boydell, 1967a,b; Kosner, 1987; Zemetra \& Morris, 1988). In most cases, these observations are based on the study of intervarietal chromosome substitution lines or the results of $F_{2}$ monosomic analysis. In many of these instances, it is not known how many genes are involved, or how significant these chromosomal effects are in controlling ear emergence rates compared with the genes on the group 2 and 5 chromosomes.

Chromosomes influencing ear-emergence but apparently not affected by vernalization or day-length have also been identified (Scarth \& Law, 
1983; Hoogendoorn, 1985). Again the actual genes involved have yet to be located.

The major Vm genes on the group 5 chromosomes actively reduce the need for vernalization requirement. This follows from the fact that spring habit or reduced vernalization is dominant. More importantly though, is the increased requirement as chromosomes carrying these $\mathrm{Vrn}$ genes are deleted and, conversely, the reduced requirement as these chromosomes are increased in dosage (Halloran, 1966). Similar effects have been found for the Ppd genes where group 2 tetrasomics and ditelosomics in the variety Chinese Spring are more insensitive and sensitive, respectively, to day-length than euploid (Scarth \& Law, 1984). The Ppd genes therefore actively reduce sensitivity to day-length.

The success of the aneuploid approach in detecting and resolving the group 2 and 5 chromosomal activities affecting ear emergence rates prompted further studies of other homoeologous groups of chromosomes and their effects on ear emergence and responses to vernalization and day-length. The most developed and well established aneuploid series in wheat is, of course, in the variety Chinese Spring (Sears, 1954), where complete sets of monosomics, ditelosomics, tetrasomics and nullisomictetrasomics are available for study. This paper describes the behaviour of the aneuploids from this variety, belonging in the main to homoeologous group 6, when grown under different day-lengths and subjected to different levels of vernalization. It was hoped that this approach would lead to the identification of other critical chromosomes controlling ear-emergence and, by so doing, accelerate the search for useful allelic variation, as well as contributing to the understanding of the flowering process in wheat.

\section{Materials and methods}

Three experiments were undertaken. The first investigated the day-length response of Chinese Spring (CS) euploid, the three monosomics of groups 2 and 6 , and the short- and long-arm ditelosomics of chromosome 6B, CS DT6BS and CS DT6BL. The ditelosomics were started after the main experiment was under way, so a second sowing of CS euploid was included to allow for this. The second experiment involved CS euploid, the three monosomics of group 6 once again and five of the available nullitetrasomics of this group, CS N6A-T6B, CS N6A-T6D, CS N6B-T6A, CS N6D-T6B and CS N6D-T6A $\quad(\mathrm{N}=$ nullisomic; $\mathrm{T}=$ tetrasomic $)$. The third experiment investigated the behaviour of CS euploid and the three tetrasomics of group 6. The genotypes in experiments 2 and 3 were subjected to different day-lengths as well as different vernalization levels.

All experiments were carried out in controlled environment cabinets. Day-length treatments involved separate cabinets, both of which received 8 $\mathrm{h}$ of high intensity fluorescent lighting supplemented with additional low incandescent light to improve the spectrum quality. For the remaining $16 \mathrm{~h}$, the short-day cabinet received no light whereas the longday cabinet was illuminated with low intensity incandescent light only. The temperature was maintained in experiment 1 at $18 \pm 1^{\circ} \mathrm{C}$ throughout the day and night lighting regimes. In the remaining experiments the temperature was raised to $20 \pm 1^{\circ} \mathrm{C}$.

In experiments 2 and 3 , half the plants from each of the genotypes were germinated and then given a 30 -day period of cold treatment at $4-6^{\circ} \mathrm{C}$ to meet their vernalization requirements. Unvernalized plants were germinated at a later date than those undergoing vernalization to ensure that all the plants entered the cabinets at a similar growth stage.

Throughout all the experiments, plants were re-randomized at intervals to minimize possible competition effects. Plants were fed with phosphogen liquid fertilizer every 2 weeks and were sprayed with Bayleton, a systemic fungicide, as required to prevent fungal infection.

All plants grown in the experiments were checked cytologically by examining root tip squashes stained with Feulgan to confirm their chromosome status. Four plants were grown for each genotype, in each treatment, in each of the experiments.

The days taken to ear-emergence, from the first day plants were placed in the controlled environment cabinet to spike emergence, were recorded for each plant.

\section{Statistical comparisons}

Genotypic means were compared using a $t$-test. Chromosome interactions with the environment were estimated using the model derived from Mather \& Jinks (1971) and shown in Table 1, where $m$ refers to the mid-point, $[d]$ to the mean genetic difference between the CS aneuploid line and CS euploid, $e_{\mathrm{v}}$ to the mean effect of the vernalization treatment, $e_{\mathrm{p}}$ to the mean effect of the day-length or photoperiodic treatment, $e_{\mathrm{pv}}$ to the mean effect of the interaction between vernalization and day-length treatments, $g_{\mathrm{v}}$ to the interaction between the genetic difference and vernalization, $g_{p}$ to the interaction between the genetic difference and day-length and 
$g_{\mathrm{pv}}$ to the interaction between the genetic difference and the interaction between vernalization and day-length. The orthogonal comparisons for each of these parameters, along with the derivation of their standard errors, are also shown in Table 1.

In the first experiment, only day-length treatments were used. This simplifies the model and only four orthogonal comparisons as opposed to eight are possible.

\section{Nullisomic-tetrasomics}

These genotypes, in which one group 6 chromosome is missing and compensated for by increasing the dosage of a related homoeologue, can be usefully exploited not only in determining the effect of the missing chromosome but also the interaction between homoeologues. This follows from the fact that each nulli-tetrasomic has a reciprocal partner which when intercrossed should give rise to the euploid chromosome configuration, e.g. CS N6A-T6B $\times$ CS N6B-T6A $=$ CS euploid. Each reciprocal nulli-tetrasomic combination can thus be regarded as the parents of a cross and the euploid as the $F_{1}$. The position of the euploid relative to the midpoint between the two nulli-tetrasomics is therefore a measure of interaction between the two homoeologues. This useful property was first pointed out by Law (1983) and has been used to effect in the study of the chromosomal control of the bread-making character, SDS-sedimentation volume (Rogers et al., 1988). In the second experiment, because one nulli-tetrasomic is missing, only two reciprocal nulli-tetrasomic combinations are available for analysis. For each of these combinations, the coefficients used to estimate, by the method of weighted least squares (Mather \& Jinks, 1971), the chromosomal and interaction effects, $[d]$ and $[c]$, respectively, as well as their interactions with vernalization and day-length are given in Table 2.

\section{Results}

\section{Experiment 1}

The ear-emergence values for CS euploid and CS ditelocentric 6BS under short- and long-days are given in Table 3 .

The long-arm ditelocentric, CS DT6BL, was also grown but, under short-days, developing seedlings exhibited 'corroded' symptoms as a result of the absence of the gene co located on the short-arm (Sears, 1954). The symptoms were not as clearly expressed under long-days indicating the involvement of day-length in their expression. Under shortdays, the corroded symptoms manifested themselves as white bands across each leaf blade. The study of the control of the width and number of these bands within a single leaf developed as an off-shoot of this experiment and is described by Islam-Faridi (1988). Because the corroded symptoms affected the growth of the plant and in particular the progression to ear-emergence, CS DT6BL was removed from the analysis.

Table 1 Orthogonal comparisons between CS euploid and a CS aneuploid wheat grown under long- and short-days and vernalized and unvernalized conditions

\begin{tabular}{|c|c|c|c|c|}
\hline & $\begin{array}{l}\text { Short-days } \\
\text { Unvernalized }\end{array}$ & $\begin{array}{l}\text { Short-days } \\
\text { Vernalized }\end{array}$ & $\begin{array}{l}\text { Long-days } \\
\text { Unvernalized }\end{array}$ & $\begin{array}{l}\text { Long-days } \\
\text { Vernalized }\end{array}$ \\
\hline $\begin{array}{l}\text { CS euploid } \\
\text { CS aneuploid }\end{array}$ & $\begin{array}{l}\bar{x}_{1} \\
\bar{x}_{5}\end{array}$ & $\begin{array}{l}\bar{x}_{2} \\
\bar{x}_{6}\end{array}$ & $\begin{array}{l}\bar{x}_{3} \\
\bar{x}_{7}\end{array}$ & $\begin{array}{l}\bar{x}_{4} \\
\bar{x}_{8}\end{array}$ \\
\hline \multicolumn{5}{|c|}{$\begin{array}{l}m=1 / 8\left(\bar{x}_{1}+\bar{x}_{2}+\bar{x}_{3}+\bar{x}_{4}+\bar{x}_{5}+\bar{x}_{6}+\bar{x}_{7}+\bar{x}_{8}\right) \\
{[d]=1 / 8\left(\bar{x}_{1}+\bar{x}_{2}+\bar{x}_{3}+\bar{x}_{4}-\bar{x}_{5}-\bar{x}_{6}-\bar{x}_{7}-\bar{x}_{8}\right)} \\
e_{\mathrm{v}}=1 / 8\left(\bar{x}_{1}-\bar{x}_{2}+\bar{x}_{3}-\bar{x}_{4}+\bar{x}_{5}-\bar{x}_{6}+\bar{x}_{7}-\bar{x}_{8}\right) \\
e_{\mathrm{p}}=1 / 8\left(\bar{x}_{1}+\bar{x}_{2}-\bar{x}_{3}-\bar{x}_{4}+\bar{x}_{5}+\bar{x}_{6}-\bar{x}_{7}-\bar{x}_{8}\right) \\
e_{\mathrm{pv}}=1 / 8\left(\bar{x}_{1}-\bar{x}_{2}-\bar{x}_{3}+\bar{x}_{4}+\bar{x}_{5}-\bar{x}_{6}-\bar{x}_{7}+\bar{x}_{8}\right) \\
g_{\mathrm{v}}=1 / 8\left(\bar{x}_{1}-\bar{x}_{2}+\bar{x}_{3}-\bar{x}_{4}-\bar{x}_{5}+\bar{x}_{6}-\bar{x}_{7}+\bar{x}_{8}\right) \\
g_{\mathrm{p}}=1 / 8\left(\bar{x}_{1}+\bar{x}_{2}-\bar{x}_{3}-\bar{x}_{4}-\bar{x}_{5}-\bar{x}_{6}+\bar{x}_{7}+\bar{x}_{8}\right) \\
g_{\mathrm{pv}}=1 / 8\left(\bar{x}_{1}-\bar{x}_{2}-\bar{x}_{3}+\bar{x}_{4}-\bar{x}_{5}+\bar{x}_{6}+\bar{x}_{7}-\bar{x}_{8}\right)\end{array}$} \\
\hline \multicolumn{5}{|c|}{$\mathrm{SE}=1 / 8\left(\mathrm{~V} \bar{x}_{1}+\mathrm{V} \bar{x}_{2}+\mathrm{V} \bar{x}_{3}+\mathrm{V} \bar{x}_{4}+\mathrm{V} \bar{x}_{5}+\mathrm{V} \bar{x}_{6}+\mathrm{V} \bar{x}_{7}+\mathrm{V} \bar{x}_{8}\right)^{1 / 2}$} \\
\hline
\end{tabular}

$\bar{x}_{1}, \ldots, \bar{x}_{8}$ refer to the mean ear-emergence times. 
Table 2 Coefficients used to estimate the 12 parameters describing genetic differences in ear-emergence time in wheat between reciprocal nulli-tetrasomics and their interactions with vernalization and day-length

\begin{tabular}{|c|c|c|c|c|c|c|c|c|c|c|c|c|c|}
\hline Line & Treatment & $m$ & {$[d]$} & {$[c]$} & $e_{\mathrm{v}}$ & $e_{\mathrm{p}}$ & $e_{\mathrm{vp}}$ & $g_{\mathrm{dv}}$ & $g_{\mathrm{cv}}$ & $g_{\mathrm{dp}}$ & $g_{\mathrm{cp}}$ & $g_{\mathrm{dvp}}$ & $g_{\text {cup }}$ \\
\hline N6AT6B & UVS & 1 & 1 & & 1 & 1 & 1 & 1 & \multirow{3}{*}{1} & 1 & \multirow{3}{*}{1} & 1 & \\
\hline Euploid & UVS & 1 & & 1 & 1 & 1 & 1 & & & & & & 1 \\
\hline N6BT6A & UVS & 1 & -1 & & 1 & 1 & 1 & -1 & & -1 & & -1 & \\
\hline N6AT6B & UVL & 1 & 1 & & 1 & -1 & -1 & 1 & \multirow{3}{*}{1} & -1 & \multirow{3}{*}{-1} & -1 & \\
\hline Euploid & UVL & 1 & & 1 & 1 & -1 & -1 & & & & & & \multirow[t]{2}{*}{-1} \\
\hline N6BT6A & UVL & 1 & -1 & & 1 & -1 & -1 & -1 & & 1 & & 1 & \\
\hline N6AT6B & VS & 1 & 1 & & -1 & 1 & -1 & -1 & \multirow{3}{*}{-1} & 1 & \multirow{3}{*}{1} & -1 & \multirow{3}{*}{-1} \\
\hline Euploid & VS & 1 & & 1 & -1 & 1 & -1 & & & & & & \\
\hline N6BT6A & VS & 1 & -1 & & -1 & 1 & -1 & 1 & & -1 & & 1 & \\
\hline N6AT6B & VL & 1 & 1 & & -1 & -1 & 1 & -1 & \multirow{3}{*}{-1} & -1 & \multirow{3}{*}{-1} & 1 & \\
\hline Euploid & VL & 1 & & 1 & -1 & -1 & 1 & & & & & & 1 \\
\hline N6BT6A & VL & 1 & -1 & & -1 & -1 & 1 & 1 & & 1 & & -1 & \\
\hline
\end{tabular}

In this table, the nulli-tetrasomics for $6 \mathrm{~A}$ and $6 \mathrm{~B}$ are used as an example.

UV, unvernalized; V, vernalized; L, long-days; S, short-days.

The parameters used to define the variation in this experiment are the same as those defined in the text, except for additional parameters to describe the departure of CS Euploid from the midpoint between the two reciprocal nullitetrasomics, designated as $[c]$ and measuring between-chromosome interaction, and its interaction with the environment, designated as $g_{\mathrm{c} v}, g_{\mathrm{cp}}$ and $g_{\mathrm{cvp}}$.

Under long-days, CS DT6BS flowered 6 days earlier than CS euploid, whereas under short-days the same genotype was over 12 days later. This is reflected in the highly significant estimate of $g_{p}$, the interaction between day-length and the absence/ presence of the long-arm of $6 \mathrm{~B}$. This result suggests that a gene(s) for day-length insensitivity is located on this arm. However, the acceleration of ear-emergence time under long-days also suggests the activity of a gene(s) for delaying ear-emergence. When this gene is removed as in CS DT6BS, ear-emergence is accelerated. It is possible that the same gene or genes is responsible for both the day-length response and the delay in ear-emergence.

The results for the monosomics of group 2 and 6 are also given in Table 3, along with the estimates for $[d], g_{\mathrm{p}}$ and $e_{\mathrm{p}}$ for each chromosome in turn. The results from the group 2 monosomics are as expected. The major differences are found for chromosome $2 \mathrm{~B}$ where significant positive $[d]$ and $g_{\mathrm{p}}$ estimates occur, presumably reflecting the previously known location of $P p d 2$ on this chromosome (Scarth \& Law, 1983). Reduced dosage of this dominant gene would be expected to delay ear-emergence under short-days, the situation found in this experiment.

The monosomics of group 6 are however different in their behaviour. Each of the three monosomics flowers earlier than CS euploid under both longand short-days. This is reflected in the significant $[d]$ and the insignificant $g_{\mathrm{p}}$ estimates for each chromosome. As for CS DT6BS under long-days, reduced chromosome dosage results in accelerated ear-emergence times but in this case under both long- and short-days. There is no evidence of an interaction with day-length. The absence of a day-length response in this case may be explained by chromosome dosage. The gene(s) for day-length insensitivity detected on the long-arm of $6 \mathrm{~B}$ may be hemizygous effective so that the loss of both doses of the gene may be required to elicit a response. In this respect it may be a less potent gene than $P p d 2$ on chromosome $2 \mathrm{~B}$. The gene(s) delaying ear emergence time, on the other hand, would seem to show a degree of hemizygous ineffectiveness so that their influence is detected when gene dosage is reduced by one. This proposed difference in behaviour would suggest that the two gene systems on these chromosomes are independent.

\section{Experiments 2 and 3}

The previous experiment examined the influence of day-length on the monosomics of group 6. Experiments 2 and 3 extended the investigation to examine the influence of both vernalization and day-length 
Table 3 Mean days to ear-emergence for CS euploid wheat, CS DT6BS and monosomics of groups 2 and 6 grown under short- and long-days

\begin{tabular}{lccccccc}
\hline Genotypes & Long-days & $\begin{array}{c}\text { Diff. from } \\
\text { euploid }\end{array}$ & Short-days & $\begin{array}{c}\text { Diff. from } \\
\text { euploid }\end{array}$ & {$[d]$} & $g_{\mathrm{p}}$ & $e_{\mathrm{p}}$ \\
\hline CS euploid & $51.00 \pm 0.41$ & & $90.00 \pm 1.58$ & & & & \\
CS DT6BS & $45.25 \pm 1.70$ & $-5.75^{*}$ & $102.25 \pm 1.44$ & $12.25^{* *}$ & $1.63^{*}$ & $4.40^{* * * *}$ & $24.00^{* * *}$ \\
CS euploid & $50.50 \pm 0.42$ & & $94.67 \pm 0.78$ & & & & \\
CS mono 2A & $49.00 \pm 4.00$ & -1.50 & $92.67 \pm 0.11$ & -2.00 & 0.88 & 0.13 & $22.96^{* * *}$ \\
CS mono 2B & $52.33 \pm 0.44$ & -1.83 & $102.00 \pm 0.50$ & $7.00^{* *}$ & $2.29^{* * *}$ & $1.38^{* * *}$ & $23.46^{* * *}$ \\
CS mono 2D & $51.67 \pm 0.78$ & 1.17 & $97.00 \pm 0.50$ & 2.33 & $0.87^{*}$ & 0.29 & $22.38^{* * *}$ \\
CS mono 6A & $45.33 \pm 2.08$ & $-5.17^{*}$ & $85.25 \pm 1.40$ & $-9.42^{* * *}$ & $3.65^{* * *}$ & 1.06 & $21.03^{* * *}$ \\
CS mono 6B & $47.67 \pm 0.44$ & $-2.83^{*}$ & $92.75 \pm 1.06$ & -1.92 & $1.19^{*}$ & -0.23 & $22.31^{* * *}$ \\
CS mono 6D & $45.33 \pm 1.78$ & $-5.17^{*}$ & $89.25 \pm 0.73$ & $-5.42^{* *}$ & $2.65^{* * *}$ & 0.06 & $22.02^{* * *}$ \\
\hline
\end{tabular}

Estimates of $[d], e_{\mathrm{p}}$ and $g_{\mathrm{p}}$ are also given.

${ }^{*} P=0.05-0.01,{ }^{*} P=0.01-0.001,{ }^{* * *} P<0.001$.

Table 4 Mean days to ear-emergence of CS euploid wheat and group 6 aneuploids of CS grown in controlled environments and subjected to different day-length and vernalization treatments

\begin{tabular}{|c|c|c|c|c|c|c|c|c|}
\hline \multirow[b]{2}{*}{ Genotypes } & \multicolumn{4}{|c|}{ Vernalized } & \multicolumn{4}{|c|}{ Unvernalized } \\
\hline & Long-days & Diff.CS & Short-days & Diff.CS & Long-days & Diff. CS & Short-days & Diff. CS \\
\hline CS euploid & $34.42 \pm 0.34$ & & $68.17 \pm 0.66$ & & $49.25 \pm 0.25$ & & $90.25 \pm 1.03$ & \\
\hline CS M6A & $33.25 \pm 0.75$ & -1.17 & $65.75 \pm 0.48$ & $-2.42^{*}$ & $39.75 \pm 0.63$ & $-9.50 * * *$ & $81.75 \pm 1.55$ & $-8.50 * * *$ \\
\hline CS M6B & $35.75 \pm 0.75$ & 1.33 & $70.00 \pm 0.41$ & $1.83^{*}$ & $42.75 \pm 0.48$ & $-6.50 * * *$ & $88.25 \pm 1.55$ & -2.00 \\
\hline CS M6D & $33.75 \pm 0.48$ & -0.67 & $66.50 \pm 0.65$ & -1.67 & $39.75 \pm 0.48$ & $-9.50 * * *$ & $83.00 \pm 1.58$ & $-7.25^{* * *}$ \\
\hline CS N6A-T6B & $33.25 \pm 0.48$ & -1.17 & $65.00 \pm 0.91$ & $-3.17^{*}$ & $48.75 \pm 0.48$ & -0.50 & $83.75 \pm 1.70$ & $-5.67^{*}$ \\
\hline CS N6A-T6D & $36.25 \pm 0.25$ & $1.83^{* * *}$ & $70.50 \pm 1.04$ & 2.33 & $54.00 \pm 0.91$ & $4.75^{* * *}$ & $98.75 \pm 2.10$ & $9.33 * *$ \\
\hline CS N6B-T6A & $38.25 \pm 0.48$ & $3.83^{* * *}$ & $67.50 \pm 0.65$ & -0.67 & $62.00 \pm 1.47$ & $12.75^{* * *}$ & $101.25 \pm 2.59$ & $11.83 * * *$ \\
\hline CS N6D-T6A & $40.00 \pm 0.41$ & $5.58^{* * *}$ & $76.00 \pm 0.58$ & $7.83^{* * *}$ & $44.50 \pm 0.50$ & $-4.75 * * *$ & $81.75 \pm 0.48$ & $-7.67^{* * *}$ \\
\hline CS N6D-T6B & $36.50 \pm 0.50$ & $2.08^{* *}$ & $75.50 \pm 1.26$ & $7.33^{* * *}$ & $41.00 \pm 0.58$ & $-8.25^{* * *}$ & $80.00 \pm 0.71$ & $-9.42 * * *$ \\
\hline CS euploid & $31.25 \pm 0.25$ & & $75.80 \pm 0.37$ & & $46.33 \pm 0.33$ & & $102.00 \pm 0.91$ & \\
\hline CS T6A & $35.25 \pm 0.63$ & $4.25^{* * *}$ & $83.60 \pm 0.51$ & $7.80^{* * *}$ & $71.75 \pm 1.32$ & $25.42^{* * *}$ & $131.00 \pm 5.57$ & $29.00 * * *$ \\
\hline CS T6B & $34.00 \pm 0.58$ & $3.00^{* *}$ & $74.75 \pm 1.18$ & -1.05 & $61.75 \pm 0.95$ & $15.42 * * *$ & $112.00 \pm 1.15$ & $10.00^{* * *}$ \\
\hline CS T6D & $37.00 \pm 0.58$ & $6.00^{* * *}$ & $81.20 \pm 1.39$ & $5.40^{* *}$ & $66.25 \pm 0.75$ & $19.92 * * *$ & $122.00 \pm 2.65$ & $20.00 * * *$ \\
\hline
\end{tabular}

${ }^{*} P=0.05-0.01,{ }^{* *} P=0.01-0.001,{ }^{* * *} P<0.001$.

on the ear-emergence times of aneuploids of group 6 having increased as well as reduced chromosome dosage. The results of both experiments are given in Table 4. The most striking feature of these results is the delayed ear-emergence times of all three tetrasomics. For example, under unvernalized short-days, CS tetrasomic $6 \mathrm{~A}$ is nearly 30 days later than CS euploid. The monosomics follow the pattern of the previous experiment and are all earlier than CS euploid, whereas the nulli-tetrasomics fall between the monosomics and tetrasomics, some being earlier than CS euploid, others later. These differences are shown in Table 5 along with the estimates of the chromosomal effects and chromosome/treatment interactions. These estimates indicate that the chromosomal effects on delaying ear-emergence interact very strongly with vernalization, the treatment reducing the effects. The day-length sensitivity of chromosome $6 \mathrm{~B}$ is also apparent in these experiments, monosomic $6 \mathrm{~B}$, tetrasomic $6 \mathrm{~B}$ and two of the nulli-tetrasomics involving this chromosome giving significant interactions with day-length.

In terms of potency, chromosome $6 \mathrm{~A}$ appears to be more potent than $6 \mathrm{D}$ because tetrasomic $6 \mathrm{~A}$ is later than tetrasomic $6 \mathrm{D}$, and monosomic $6 \mathrm{~A}$ is slightly earlier than monosomic $6 \mathrm{D}$. On the other hand, both $6 \mathrm{~A}$ and $6 \mathrm{D}$ are more potent than $6 \mathrm{~B}$ as both tetrasomics and monosomics for $6 \mathrm{~A}$ and $6 \mathrm{D}$ 
are later and earlier, respectively, than their counterparts for $6 \mathrm{~B}$. The delays in emergence are much greater for the tetrasomics compared with the accelerated emergence shown by the monosomics. This may be explained by the different chromosome dosages involved; tetrasomics have an increase of two doses, monosomics a reduction of only one.

\section{Nulli-tetrasomic analyses}

The analyses of the two reciprocal nulli-tetra combinations, CS N6A-T6B vs. CS N6B-T6A vs. euploid, and CS N6A-T6D vs. CS N6D-T6A vs. euploid by means of weighted least squares are shown in Table 6. This involves the estimation of 12 parameters defined and listed in the Table.

In both analyses, $[d]$ and $[c]$ are highly significant. Interactions between the chromosomes of group 6 therefore take place, the direction of the interaction being negative and consequently towards accelerating ear-emergence. This is rather surprising as chromosome dosage indicates that it is the activity of the genes concerned which delays ear-emergence. Dominance or interaction between chromosomes would therefore be expected to be positive. Also, the [d] estimates indicate that chromosome 6D has a greater effect than $6 \mathrm{~A}$ in delaying emergence. This contrasts with the behaviour of the monosomics and tetrasomics where 6A appears to be the more potent. The greater effect of $6 \mathrm{D}$ follows also from the behaviour of CS N6D-T6B, the one remaining nulli-tetrasomic not included in the comparative analysis. Under unvernalized conditions this line emerges earlier than CS euploid. This is as expected, and follows from the lack of compensation provided by $6 \mathrm{~B}$, the least potent of the chromosomes. However, this nulli-tetrasomic is earlier than CS N6A-T6B indicating that $6 \mathrm{D}$ contributes more than $6 \mathrm{~A}$ to delaying ear emergence.

In the second comparative analysis, involving CS N6B-T6A and CS N6A-T6B, the $[d]$ estimate for 6A vs. $6 \mathrm{~B}$ is very large, showing that $6 \mathrm{~A}$ is much more potent than $6 \mathrm{~B}$. This is in agreement with the earlier assessments of potency. Unfortunately, the absence of CS N6B-T6D from the experiment makes it impossible to evaluate the $6 \mathrm{D}$ vs. $6 \mathrm{~B}$ comparison by this method of analysis. This would provide a further check as to whether $6 \mathrm{~A}$ or $6 \mathrm{D}$ was the more potent chromosome. The presence of between-chromosome

Table 6 Estimates of parameters for ear-emergence time in wheat for the reciprocal nulli-tetrasomic combinations, CS N6A-T6B and CS N6B-T6A, and CS N6A-T6D and CS N6D-T6A

\begin{tabular}{lrr}
\hline Parameter & CS 6A vs. 6B & \multicolumn{1}{c}{ CS 6D vs. 6A } \\
\hline$m$ & $62.47 \pm 0.46^{* * *}$ & $62.71 \pm 0.34^{* * *}$ \\
{$[d]$} & $4.78 \pm 0.46^{* * *}$ & $2.16 \pm 0.34^{* * *}$ \\
{$[c]$} & $-1.95 \pm 0.56^{* * *}$ & $-2.20 \pm 0.47^{* * *}$ \\
$e_{\mathrm{v}}$ & $11.47 \pm 0.46^{* * *}$ & $7.03 \pm 0.34^{* * *}$ \\
$e_{\mathrm{p}}$ & $16.91 \pm 0.46^{* * *}$ & $19.03 \pm 0.34^{* * *}$ \\
$e_{\mathrm{vp}}$ & $1.66 \pm 0.46^{* * *}$ & $1.47 \pm 0.34^{* * *}$ \\
$g_{\mathrm{dv}}$ & $2.91 \pm 0.46^{* * *}$ & $4.47 \pm 0.34^{* * *}$ \\
$g_{\mathrm{dp}}$ & $0.22 \pm 0.46$ & $0.72 \pm 0.34^{*}$ \\
$g_{\mathrm{dvp}}$ & $0.84 \pm 0.46$ & $1.16 \pm 0.34^{* *}$ \\
$g_{\mathrm{cv}}$ & $-2.24 \pm 0.56^{* * *}$ & $2.20 \pm 0.47^{* * *}$ \\
$g_{\mathrm{cp}}$ & $1.78 \pm 0.56^{* * *}$ & $-0.34 \pm 0.47$ \\
$g_{\mathrm{cvp}}$ & $0.16 \pm 0.56$ & $0.34 \pm 0.47$ \\
\hline
\end{tabular}

${ }^{*} P=0.05-0.01,{ }^{* *} P=0.01-0.001,{ }^{* * *} P<0.001$.
Table 5 Estimates of $[d]$ for ear-emergence time in wheat and its interaction with vernalization, $g_{v}$, day-length, $g_{\mathrm{p}}$, and vernalization/ day-length interaction, $g_{\mathrm{vp}}$

\begin{tabular}{lllllr}
\hline Comparison & Genotype & {$[d]$} & $g_{\mathrm{v}}$ & $g_{\mathrm{p}}$ & \multicolumn{1}{c}{$g_{\mathrm{vp}}$} \\
\hline \multirow{2}{*}{ Monosomic vs. CS } & CS M6A & $2.70^{* * *}$ & $1.80^{* * *}$ & 0.03 & -0.28 \\
& CS M6B & $0.67^{*}$ & $1.46^{* * *}$ & $-0.63^{*}$ & -0.50 \\
& CS M6D & $2.39^{* * *}$ & $1.80^{* * *}$ & -0.16 & -0.41 \\
Tetrasomic vs. CS & CS T6A & $8.28^{* * *}$ & $5.33^{* * *}$ & -0.92 & -0.03 \\
& CS T6B & $3.39^{* * *}$ & $2.97^{* * *}$ & $-1.15^{* * *}$ & -0.20 \\
& CS T6D & $6.38^{* * *}$ & $3.40^{* * *}$ & -0.03 & 0.05 \\
Nulli-tetrasomic vs. CS CS N6A-T6B & $1.42^{* * *}$ & 0.33 & $1.00^{* * *}$ & 0.50 \\
& CS N6A-T6D & $-2.18^{* * *}$ & $-1.14^{* *}$ & -0.53 & -0.41 \\
& CS N6B-T6A & $-3.36^{* * *}$ & $-2.58^{* * *}$ & $0.78^{*}$ & 0.35 \\
& CS N6D-T6A & -0.02 & $3.33^{* * *}$ & 0.19 & $0.75^{*}$ \\
& CS N6D-T6B & $1.14^{* * *}$ & $3.49^{* * *}$ & -0.41 & $0.91 * *$ \\
\hline
\end{tabular}

${ }^{*} P=0.05-0.01,{ }^{* *} P=0.01-0.001,{ }^{* * *} P<0.001$. 
interactions may however make it difficult to rank the effects of the chromosomes accurately.

Both the interaction terms, $g_{\mathrm{dv}}$ and $g_{\mathrm{cv}}$, are significant in both analyses indicating, as might be expected from the earlier analysis, that vernalization reduces the effects of the chromosomes in delaying ear-emergence. For the day-length interactions, only $g_{\mathrm{cp}}$ for the $6 \mathrm{~A}$ vs. $6 \mathrm{~B}$ analysis is highly significant. As this comparison involves $6 \mathrm{~B}$, it is not surprising that such an effect should appear, although it is perhaps unexpected to find that the interaction involves $[c]$ rather than $[d]$. However, in the $6 \mathrm{D}$ vs. $6 \mathrm{~A}$ analysis, the $g_{\mathrm{dp}}$ and $g_{\mathrm{dvp}}$ interactions are significant, suggesting that the response to day-length can also be influenced by one or both of these chromosomes.

\section{Discussion}

The most interesting feature to emerge from this work is the delayed ear-emergence following increased dosage of the group 6 chromosomes, and the reduction in this delay by vernalization treatment. These effects are brought out most clearly in Fig 1. A similar result was observed for the group 1 chromosomes of Chinese Spring, particularly chromosome 1A (E. Y. Suarez et al., unpublished data), but the magnitude of the effects is smaller than those reported here.

The simplest way of explaining the group 6 effects is to propose that these chromosomes carry genes which produce an ear-emergence inhibitor, and that this or the genes themselves are sensitive to vernalization. Inhibitors of flowering have been found in peas (Murfet, 1989), but this would be the first indication that an inhibitor occurs in wheat. The production of an environmentally sensitive inhibitor could be an important first step in the regulation of flowering through vernalization. A second step could involve the vernalization requiring $V r n$ genes on the group 5 chromosomes. If these were to produce a flowering promotor which acted by suppressing the inhibitor genes on the group 6 chromosomes, or inactivated the inhibitor by complexing with it, then the two systems would be linked. Vrn genes for reduced vernalization requirement would produce more promotor, thereby reducing the amount of inhibitor and the need for vernalization. Removal of the $V r n$ genes would have the reverse effect (Law et al., 1993).

Another important discovery is the day-length insensitivity of a gene(s) on the long-arm of chromosome 6B. This is most evident in CS DT6BS, but its influence is also apparent in the behaviour of most of the aneuploids involving reductions or increases in the dosage of this chromosome. Also, there is some evidence from one of the analyses that there may be related day-length sensitive genes on $6 \mathrm{~A}$ or $6 \mathrm{D}$. Based on the behaviour of monosomic $6 \mathrm{~B}$ relative to that of monosomic $2 \mathrm{~B}$, there is a suggestion that the gene(s) for day-length insensitivity on $6 \mathrm{~B}$ is less potent than $P p d 2$ on $2 \mathrm{~B}$. However, to be certain this needs further study, the determination of the number of genes responsible for the $6 \mathrm{~B}$ effect being a first requirement.

The genes for delaying emergence appear to be independent of the gene(s) for day-length insensitivity, although both sets of genes may be located on the long arms of the group 6 chromosomes.

At the moment, the existence of allelic variation amongst these genes is unknown. As mentioned in the introduction, group 6 chromosomal effects on ear-emergence time have been reported previously,

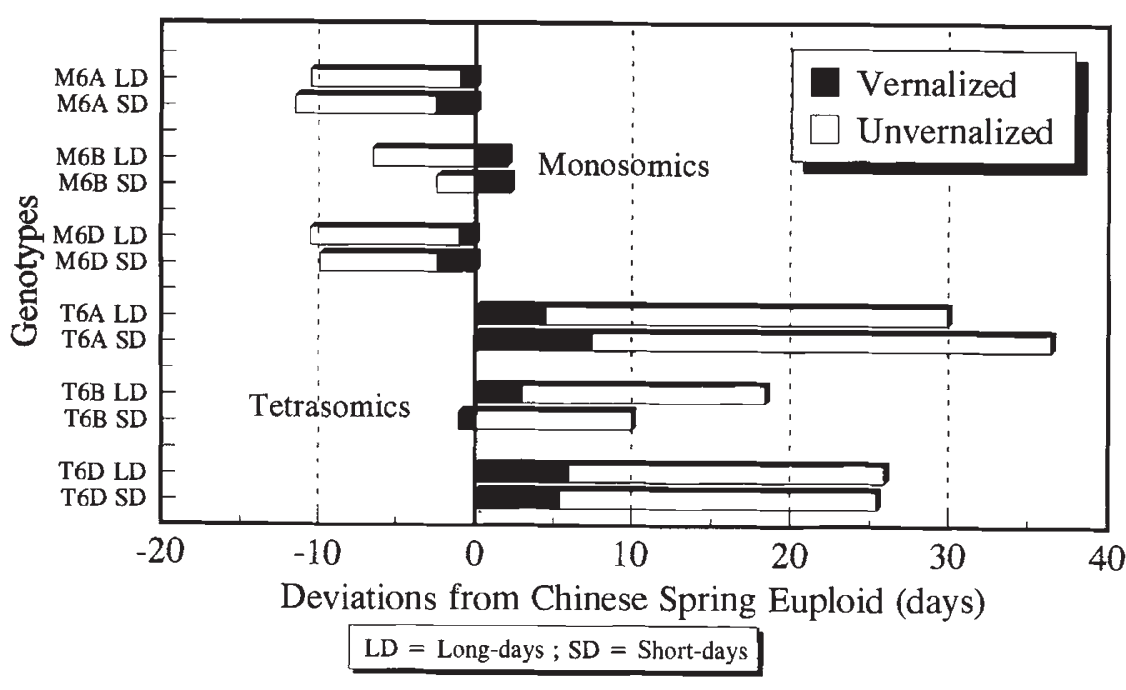

Fig. 1 Group 6 aneuploids - ear-emergence times 
so it is possible that these may be related to the genes revealed in this study. Indeed, chromosome 6B was cited by Morrison (1960) and Halloran \& Boydell (1967b) as conferring sensitivity to day-length. Both studies involved Chinese Spring as one of the parents so this is in agreement with the behaviour of CS DT6BS in the present study. A major effect of chromosome 6D of Bezostaya 1 substituted into Cappelle-Desprez was reported by Law (1987) but this appeared to behave as a flowering per se gene. Subsequent analysis has however shown that much of this effect was caused by background variation and not by genes on chromosome $6 \mathrm{D}$. There is therefore little evidence for allelic variation among the genes for delaying ear-emergence and sensitive to vernalization. The present analysis has shown that homoeo-allelic variation most probably exists between the homoeologous group 6 chromosomes. This is surely the basis of the different degrees of potency between the chromosomes. To actually study the genes responsible for these effects, allelic variation needs to be found within homologues so that the number of genes and their locations can be established. Alternatively, it may be possible to uncover the genes through molecular means using reverse genetics.

At the more practical level, the consequences of such allelic variation in wheat breeding will need to be explored. Possibly, the earliest spring wheats have already been selected for group 6 genes which have a minimal effect on delaying ear-emergence. The converse may have occurred for extreme winter wheats. If so, then such varieties will be able to provide the allelic variation that is needed to further this analysis. It might then also be possible to determine the pleiotropic effects of such genes on characters other than ear-emergence time, as well as further to stimulate work on understanding the processes of flowering control in wheat.

\section{Acknowledgements}

The authors would like to thank Dr J. W. Snape for his help with the least squares analysis. CNL wishes to recognise the help of the Leverhulme Trust in awarding him an Emeritus Fellowship enabling him to complete the analysis and writing of this work.

\section{References}

HALlORAN, G. M. 1966. Gene dosage and vernalization response in homoeologous group 5 of Triticum aestivum. Genetics, 57, 401-407.

HALLORAN, G. M. AND BOYDELL, c. W. 1967a. Wheat chromosomes with genes for vernalization response. Can. J. Genet. Cytol, 9, 632-639.

HALLORAN, G. M. AND BOYDELL, C. w. 1967b. Wheat chromosomes with genes for photoperiodic response. Can. J. Genet. Cytol, 9, 394-398.

HoOGENDOORN, J. 1985. A reciprocal $F_{1}$ monosomic analysis of the genetic control of time to ear-emergence, number of leaves and number of spikelets in wheat (Triticum aestivum L.). Euphytica, 34, 545-558.

ISLAM-FARIDI, M. N. 1988. Genetical Studies of Grain Protein and Developmental Characters in Wheat. Ph.D. Thesis, University of Cambridge, U.K.

KLAIMI, Y. Y. AND QUALSET, C. O. 1973. Genetics of heading time in wheat (Triticum aestivum L.). 1. The inheritance of photoperiodic response. Genetics, 74, 139-156.

KOSNER, J. 1987. A study of inheritance in the alternative growth habit of the cultivar Ceska Presivka. Scientia Agriculturae Bohemoslovaca, 19, 33-45.

LAW, C. N. 1966 The location of genetic factors affecting a quantitative character in wheat. Genetics, 53, 487-498.

LAw, C. N. 1983. Chromosome engineering in wheat breeding and its implications for molecular genetic engineering. In: Setlow, J.K. and Hollaender, A. (eds) Genetic Engineering: Principles and Methods, vol. 5, pp. 157-172. Plenum Press, New York.

LAW, C. N. 1987. The genetic control of day-length response in wheat. In: Atherton, J. G. (ed.) Manipulation of Flowering, pp. 225-240. Butterworths, London.

LAW, c. N., WORLAND, A. J. AND GIORGI, B. 1976. The genetic control of ear-emergence time by chromosomes 5A and 5D of wheat. Heredity, 36, 49-58.

LAW, C. N., SUTKA, J. AND WORLAND, A. J. 1978. A genetic study of day-length response in wheat. Heredity, 41, 185-191.

LAW, C. N., DEAN, C. AND COUPLAND, G. 1993. Genes controlling flowering and strategies for their isolation and characterization. In: Jordan, B. R. (ed.) The Molecular Biology of Flowering, pp. 47-68. CAB International, Wallingford, U.K.

MATHER, K. AND JINKS, J. L. 1971. Biometrical Genetics, 2nd edn. Chapman \& Hall, London.

MAYSTRENKO, O. I. 1980. Cytogenetic study of the growth habit and ear-emergence time in wheat (Triticum aestivum L.). In: Well-being of Mankind and Genetics. Proc. XIV Int. Congress Genetics, Moscow, vol. 1, pp. 267-282. MIR Publishers, Moscow.

MORRISON, J. w. 1960. The monosomic analysis of growth habit in winter wheat. Z. Vererbl., 91, 141-151.

MURFET, 1. C. 1989. Flowering genes in Pisum. In: Lord, E. M. and Bernier, G. (eds) Plant Reproduction: From Floral Induction to Pollination, pp. 11-18. American Society of Plant Physiologists, Rockville, Maryland.

ROGERS, W. J., LAW, C. N. AND SAYERS, E. J. 1988. Dosage effects of homoeologous group 1 chromosomes upon the bread-making quality of hexaploid wheat. In: Koebner, R. M. D. and Miller, T. E. (eds) Proceedings of the Seventh International Wheat Genetics Symposium, Cambridge, 1988, vol. 2, pp. 1003-1008. IPSR 
Cambridge.

SCARTH, R. AND LAW, C. N. 1983. The location of the photoperiodic gene, $P p d 2$, and an additional genetic factor for ear-emergence time on chromosome 2B of wheat. Heredity, 51, 607-619.

SCARTH, R. AND LAW, C. N. 1984. The control of the day-length response in wheat by the group 2 chromosomes. J. Plant Breeding, 92, 140-150.

SEARS, E. R. 1954. The aneuploids of common wheat. Res. Bull. Mo. Agr. Exp. Stat., 572, 1-59.

STELmakH, A. F. 1993. Genetic effects of $V r n$ genes on heading date and agronomic traits in bread wheat. Euphytica, 65, 53-60.
WELSH, J. R., KEIM, D. L., PIRASTAH, B. AND RICHARDS, R. D. 1973. Genetic control of photoperiod response in wheat. In: Sears, E.R. and Sears, L.M.S. (eds) Proceedings of the Fourth International Wheat Genetics Symposium, Columbia, MI, U.S.A., pp. 879-884.

WORLAND, A. J. AND LAW, C. N. 1986. Genetic analysis of chromosome 2D of wheat. 1. The location of genes affecting height, day-length insensitivity, hybrid dwarfism and yellow-rust resistance. Zeitschrift für Pflanzen, 96, 331-345.

ZEMETRA, R. S. AND MORRIS, R. 1988. Effects of an intercultivaral chromosome substitution on winterhardiness and vernalization in wheat. Genetics, 119, 453-456. 